
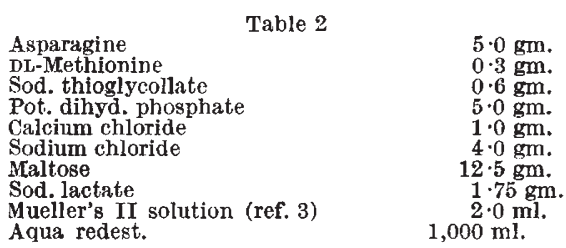

After inoculation with the pellicle from a four-day old culture of a sub-strain (adapted to the synthetic medium mentioned above) of P.W. No. 8 (Toronto Harvard) strain and eight or nine days incubation at $33-35^{\circ} \mathrm{C}$., flocculation units and median lethal dose for guinea pigs $(250-260 \mathrm{gm}$.) belonging to a vigorous stock were determined.

In 1943, Seki ${ }^{4}$ described his finding that the removal of the crystalline (tyrosine) formed during the preparation of casein acid-hydrolysate tends to decrease the toxin content (from the estimation of median lethal dose) of the culture filtrate harvested from the casein hydrolysate medium; and Linggood and Woiwod have recently shown that tyrosine is present in toxin but not in toxoid hydrolysate of diphtheria on two-dimensional paper chromatograms $^{5}$. Therefore, the possibility of an intimate connexion between the toxic group of diphtheria toxin and tyrosine present in the culture medium may be supposed, but the intrinsic significance of tyrosine is not yet clear. Further work to find the actual mechanism involved is now in progress. This will be published in detail later.

Department of Bacteriology, MASAHIKO YONEDA

School of Medicine,

Nagoya University,

Nagoya, Japan. June 10.

${ }^{1}$ Yoneda, M., Nagoya J. Med. Sci., 14, No. 2 (in the press, 1951).

${ }^{2}$ Yoneda, M., Jap. J. Bact., 15, 401 (1950); and in the press; Nature, $[16 \%, 860$ (1951) ].

${ }^{3}$ Mueller, J. H., and Miller, P. A., J. Immunol., 40, 21 (1940).

+ Seki, T., Ösaka Igakkai Z., 42, 1397 (1943) (in Japanese).

s Iinggood and Woiwod, Nature, 163, 4163 (1949).

\section{Factor Rb Activity in Human Plasma}

FACTOR $R b$ is a protein-like, heat-labile requirement of the nematode Rhabditis briggsae Dougherty and Nigon, 1949, for growth and reproduction under axenic conditions ${ }^{1,2}$; chick embryo and mammalian liver have been shown to be good sources of it, and some activity has previously been noted in human whole blood and plasma ${ }^{2}$.

It is of interest to report now that, when properly supplemented, human plasma has been shown, by recent work, to be a good source of factor $R b$. The plasma used was obtained through the courtesy of Dr. Karol A. Hok, of the Cutter Laboratories, Berkeley; it was irradiated, lyophilized material, pooled from many donors and with approximately 0.4 per cent sodium citrate included as an anticoagulant. Water was added to restore the original volume, and the liquid was sterilized by Seitz filtration. Part of the sterile product was dialysed under sterile conditions against three changes of a large volume of distilled water. Both the dialysed and undialysed material were tested as sources of factor $R b$. This was done by adding to each of a series of Neurospora growth-tubes $1 \mathrm{ml}$. of one of the plasma preparations and $1 \mathrm{ml}$. of an autoclaved liver preparation made by homogenizing horse liver with an equal weight of distilled water, centrifuging the product at $20,000 \mathrm{~g}$, autoclaving the supernatant fluid, homogenizing the product, recentrifuging at $20,000 \mathrm{~g}$, and sterilizing the clear supernatant by passing it through a Seitz filter.

I'he foregoing media have uniformly supported the production of vigorous cultures inoculated with a few dozen tiny larvæ. These results are in contrast to limited growth (maturation without successful reproduction) of larvæ placed in plasma supplemented with certain known ingredients ${ }^{2}$.

The newer results are particularly significant for the development of a defined medium for $R$. briggsae, because the protein constitution of human plasma is the best known of any complex biological material ${ }^{3}$. It will now become possible to test the plasma protein fractions already available and probably to determine in which of these the factor $R b$ activity resides. This has a great advantage over extending the tedious fractionation of liver protein already carried out ${ }^{2,4}$. It may supply a rationale for the failure of peptic digestion to release factor $R b$ activity in non-protein form from liver protein ${ }^{5}$.

The foregoing preliminary results are reported at this time by reason of the fact that further investigations on plasma protein will probably be delayed for more than half a year by projected travel abroad.

Note added in proof. My student, Douglas F. Keith, has recently been able to show that factor $R b$ activity is apparently confined to those plasma fractions rich in $\beta$-globulins (fractions III and IV). $\mathrm{He}$ is now testing subfractions of these fractions, particularly as supplemented only by known ingredients (that is, vitamins, salts, etc.).

University of California, Eulsworth C. Dougherty*

Department of Zoology, Berkeley. July 23.

* Research Fellow of the American Cancer Society as recommended by the National Research Council Committee on Growth, 1949-51. ${ }^{1}$ Dougherty, E. C., Anat. Rec., 108, 415 (1950).

${ }^{2}$ Dougherty, E. C., Exp. Parasitol., 1, 34 (1951).

${ }^{3}$ Onclcy, J. T.., Symposia on Nutrition, Robert Gould Res. Found., 2 (Plasma Proteins), 3 (1950).

- Dougherty, E. C. (unpublished data).

${ }^{5}$ Dougherty, E. C. (submitted for publication).

\section{The Rabbit Lumbrical : a New Isolated Mammalian Nerve-Muscle Preparation}

The rat diaphragm phrenic nerve preparation ${ }^{1}$ enabled mammalian muscle to be studied under precise conditions of drug and ion concentration, but is insensitive to decamethonium $(C 10)$. The object of this communication is to describe a new isolated mammalian nerve-muscle preparation which does not suffer from this disadvantage. Several muscles in the feet of rabbits and cats are suitable; but the medial lumbrical of the rabbit's hind foot has been found most satisfactory. It is usually about $18 \mathrm{~mm}$. long and $1 \mathrm{~mm}$. in diameter under physiological tension.

A rabbit is killed and bled, and the skin removed from one hind leg. It is very adherent on the plantar surface of the foot and must be carefully removed, since the nerve is immediately beneath it.

The long, very fine tendon of insertion of the medial lumbrical which passes around the medial side of the second digit is secured by a piece of silk and cut distally. Next the plantaris tendon passing to the 